\title{
Biological activity of selected plant ethanolic extracts against phytopathogenic fungi, Fusarium oxysporum f.sp. cicer
}

\author{
Farah Khameis Farag Teia ${ }^{1 *}$ and Ahmed Osman ${ }^{2}$ \\ ${ }^{1}$ Department of Agro-technology, Medicinal and Aromatic Plants and Traditional Medicine Research Institute, National \\ Centre for Research, Khartoum, Sudan. \\ ${ }^{2}$ Department of Microbiology, Medicinal and Aromatic Plants and Traditional Medicine Research Institute, National \\ Centre for Research, Khartoum, Sudan.
}

Accepted 26 February, 2018

\begin{abstract}
In this present study six different plants used in traditional Sudanese medicine; Allium sativum L. (Liliaceae), Azadirachta indica (Meliaceae), Capsicum frutescence L. (Solanaceae), Momordica balsamina (Cucurbitaceae), Petroselinum crispum (Apiaceae) and Pulicaria undulata L.(Asteraceae), were examined against Fusarium oxysporum f.sp. cicer., the causal agent of vascular wilt in chickpea. We used disc agar method to determine the in vitro antifungal activity of these plants. The ethanolic extracts of studied plants exhibited varying degrees of inhibition activity against the tested fungi. Among the 6 plants studied only two plants $(A$. sativum, $P$. crispum) showed high activity, other plants (M. Balsamina, $A$. indica, $C$. frutescence, $P$. undulata) showed moderate activity. These results suggest that the plants may have individual components that can be useful for managing Fusarium oxysporum f.sp. cicer.
\end{abstract}

Keywords: Fusarium oxysporum f.sp. cicer., inhibition activity, medicinal plants, inhibition zone.

${ }^{*}$ Corresponding author. E-mail: farfor157@gmail.com.

\section{INTRODUCTION}

Many of compounds extracted from plant have pharmacological and biological activities such as anticancer, antiviral, antibacterial, antifungal insecticidal and nematicidal effects (Pandey et al., 2000; Srinivasan et al., 2001; Soliman and Badeaa, 2002; Dissanayake and Jayasinghe, 2013; Abd-Ulgadir et al., 2015).

The interest on use of plant material has been increased as alternative of synthetic fungicides to control plant diseases. However, that is needed because of her eco-friendly and the negative public perceptions about the use of synthetic chemicals, high cost of new chemicals and resistance to fungal pathogens (Dissanayake and Jayasinghe, 2013). Therefore, researchers are doing scientific studies on traditionally used plants for the control and management of different diseases and these could be valuable sources for new natural products (Lee et al., 2007; Dwivedi and Sangeeta,
2015).

Antifungal activity of plant extracts has been studied and showed a wide range of activity against fungi, in previous studies, tested plants showed antifungal activity against several fungi such as Aspergillus sp., Penicillium sp., Rhizopus sp., Penicillium sp., Alternaria solani, Fusarium solani, Fusarium oxysporum f.sp. melonis, Macrophomina phaseolina, Candida albicans and Trichophyton sp. (Burger et al., 2010; Soumya and Bindu, 2012; Shrivastava and Kshma, 2014; Ajaib et al., 2015; Ikegbunam et al., 2016; Linde et al., 2016).

$F$. oxysporum f. sp. ciceri, associated with seeds of chickpea, and adversely affects quality and health of seeds in most of the chickpea growing areas of the world (Jalali and Chand, 1992). In addition, chickpea is the major source of food for human as well as animal food, it is a highly nutritious value (proteins, carbohydrates), also 
very good source of fibre, vitamins and minerals (Chibbar et al., 2010).

Mandhare and Suryawanshi (2009) reported that the extracts of Azadirachta indica and Allium sativum showed antifungal activity against $F$. oxysporum f.sp. ciceri., and it was the same result recorded by Singh and Chand (2004). In addition, the antifungal potential of $A$. indica was determinate on tested fungi by Mukhtar (2007) and Jibhkate et al. (2010).

But, there have been no reports of extracts obtained from Capsicum frutescence L., Momordica balsamina, Petroselinum crispum and Pulicaria undulata L.used to control Fusarium oxysporum f.sp. cicer, hence, the principle aim of the present work is to assess the biological activity of Selected Plant Ethanolic Extracts namely; garlic (Allium sativum L.), neem (Azadirachta indica), hot paper (C. frutescence L.), bitter melon (Momordica balsamina), parsley (Petroselinum crispum) and rabble (Pulicaria undulata L.), against Phytopathogenic Fungi, Fusarium oxysporum f.sp. cicer.

\section{MATERIALS AND METHODS}

\section{Plant materials}

Studied Plants were collected from different local area in Sudan, where these plants are available such as shambat- Khartoum, and Kordufan. Identified and authenticated by Herbarium unit department of phytochemistry. Herbarium material was deposited at Medicinal and Aromatic Plants and Traditional Medicine Research Institute (MAPTMRI), NCR. Khartoum. Sudan.

\section{Preparation of plants extracts}

Extracts prepared in ethanol at room temperature by simple extraction method (Sukhdev et al., 2008). Parts of plants (corms of garlic, leaves of neem, fruits of hot paper, and aerial parts of rabble, aerial parts of parsley and stems of bitter melon), were dried under room temperature, samples $(100 \mathrm{~g})$ of dried parts from each plant were aseptically weighed and placed in separate sterile glass flasks. One litre of $70 \%$ ethanol was added to each flask, then left to macerate for three days at room temperature, with occasional stirring. After this extraction period, the $70 \%$ ethanol extracts were filtered through Whatman No. 1 filter paper and these filtered extracts concentrated under reduced pressure using a rotary evaporator. Solvents (ethanol) were removed from the concentrates by incubated them into room temperature at $37^{\circ} \mathrm{C}$ for $24 \mathrm{~h}$. after full dried extracts from each plant, only $2 \mathrm{~g}$ from each plant extract were added to $2 \mathrm{ml}$ of distilled water and diluted into different concentrations $(0.1,0.05,0.025,0.012$, and $0.006 \mathrm{ppm})$.

\section{Preparation of fungal suspension}

F. oxysporum f.sp. ciceris obtained from Microbial Type Culture Collection, Central lab of Plant Pathology, Plant Protection Directorate. This fungus was grown on Sabouraud dextrose agar plate at $28^{\circ} \mathrm{C}$ and maintained with periodic sub-culturing at $4^{\circ} \mathrm{C}$. The fungal cultures of F.oxysporum f. sp. ciceris, were maintained on Sabouraud dextrose agar (SDA), incubated at $25^{\circ} \mathrm{C}$ for 7 days. The fungal growth was harvested and washed with sterile normal saline and finally suspension in $100 \mathrm{ml}$ of sterile normal saline, to produce a suspension containing about $10^{8}$ to $10^{9} \mathrm{CFU} / \mathrm{ml}$. The suspension was stored in the refrigerator at $4^{\circ} \mathrm{C}$ till used.

\section{Biological assay of antifungal activities}

We used disc agar method (NCCLS, 1999; Duru et al., 2003), to determine a biological activity of ethanol crude extract of six medicinal plants used in traditional Sudanese medicine, namely: Allium sativum L. (Liliaceae), Azadirachta indica (Miliaceae), Capsicum frutescence L. (Solanaceae), Momordica balsamina (Cucurbitaceae), Petroselinum crispum (Apiaceae) and Pulicaria undulata L.(Asteraceae), against phytopathogenic fungi, Fusarium oxospoeum f.sp. cicer. Fungal growth was swabbed uniformly on surface of Sabouraud dextrose agar, sterilized filter paper discs (Whatman No.1, $6 \mathrm{~mm}$ in diameter) were placed on the surface of the Sabouraud dextrose agar and soaked with $20 \mu \mathrm{l}$ of a solution of each plant extracts. The inoculated plates incubated into room temperature in the inverted position to allow growth of tested fungi, and for each treatment were used in triplicate, then after $24 \mathrm{~h}$, the diameters of clear zones were measured (the diameter around the filter paper disc with plant extract).

\section{RESULTS AND DISCUSSION}

Biological activity of six plants was assayed and data on effect of plant extracts on the growth of $F$. oxysporum f.sp. cicer., presented in Table 1. The extracts of studied plants exhibited varying degrees of inhibition activity against the tested fungi; the results were expressed in terms of the diameter of the growth-inhibition zone (clear zones) according to Mukhtar and Ghori (2012). Among the 6 plants studied only two plants (Allium sativum, and Petroselinum crispum) showed high activity (18 to 22 $\mathrm{mm}$ ), other plants (Momordica balsamina, Azadirachta indica, Capsicum frutescens, Pulicaria undulata) showed moderate activity (13 to $17 \mathrm{~mm}$ ).

Extracts from Capsicum frutescence L., Momordica balsamina, Petroselinum crispum and Pulicaria undulata $L$. were used for the first time to inhibit growth of $F$. oxysporum f.sp. cicer. and showed promising antifungal potentiality against tested fungi.

The best result of inhibition activity of ethanolic extracts found in the corms of garlic ( $A$. sativum), at all concentrations ( 0.006 to $0.1 \mathrm{ppm}$ ) ranging between 18 and $22 \mathrm{~mm}$, the similar result with Mandhare and Suryawanshi (2009). In a previous study, the essential oil of $P$. crispum showed antifungal activity against several of fungi such as Aspergillus sp., Penicillium sp., and Trichophyton sp. (Linde et al., 2016). However, in the present study, the ethanolic extract of parsley, also was good antifungal activity in all concentrations.

$M$. balsamina showed antifungal potential against $F$. oxysporum f.sp. cicer., the same result was found against Fusarium oxysporum f.sp. melonis (Burger et al., 2010). $A$. indica showed moderate activity against tested phytopathogen, but the lower activity found in lower concentration (0.006 ppm), in 2010 Jibhkate et al. reported that, neem seed extract had antifungal activity against $F$. oxysporum f.sp. cicer. 
Table 1. Biological activity of plant extracts of six Sudanese medicinal plants against $F$. oxysporum f.sp. cicer. (IZ; diameter of clear growth-Inhibition zone).

\begin{tabular}{|c|c|c|c|}
\hline Plant & Part used & Concentration (ppm) & Mean of IZ $(\mathrm{mm})$ \\
\hline \multirow{5}{*}{ M. balsamina (Cucurbitaceae) } & \multirow{5}{*}{ Stems } & 0.1 & 17 \\
\hline & & 0.05 & 17 \\
\hline & & 0.025 & 17 \\
\hline & & 0.012 & 16 \\
\hline & & 0.006 & 14 \\
\hline \multirow{5}{*}{ A. indica (Miliaceae) } & \multirow{5}{*}{ Leaves } & 0.1 & 17 \\
\hline & & 0.05 & 17 \\
\hline & & 0.025 & 14 \\
\hline & & 0.012 & 14 \\
\hline & & 0.006 & 12 \\
\hline \multirow{5}{*}{ P. crispum (Apiaceae) } & \multirow{5}{*}{ Aerial parts } & 0.1 & 18 \\
\hline & & 0.05 & 18 \\
\hline & & 0.025 & 18 \\
\hline & & 0.012 & 18 \\
\hline & & 0.006 & 17 \\
\hline \multirow{5}{*}{ P. undulata L. (Asteraceae) } & \multirow{5}{*}{ Aerial parts } & 0.1 & 16 \\
\hline & & 0.05 & 15 \\
\hline & & 0.025 & 15 \\
\hline & & 0.012 & - \\
\hline & & 0.006 & - \\
\hline \multirow{5}{*}{ C. frutescence L. (Solanaceae) } & \multirow{5}{*}{ Fruits } & 0.1 & 16 \\
\hline & & 0.05 & 15 \\
\hline & & 0.025 & 14 \\
\hline & & 0.012 & 14 \\
\hline & & 0.006 & 13 \\
\hline \multirow{5}{*}{ A. sativum L. (Liliaceae) } & \multirow{5}{*}{ Corms } & 0.1 & 22 \\
\hline & & 0.05 & 22 \\
\hline & & 0.025 & 19 \\
\hline & & 0.012 & 19 \\
\hline & & 0.006 & 18 \\
\hline
\end{tabular}

Soumya and Bindu, reported in 2012, that aqueous leaf and fruit extracts of $C$. frutescens had effectiveness against Aspergillus flavus, $A$. niger, Penicillium sp. and Rhizopus sp fruit. But the fruit extract were lower compared to the leaf extract. In the present work, $C$. frutescens showed moderate activity against tested fungi in all concentration ranging between 13 and $16 \mathrm{~mm}$.

In this study work no inhibition zone recorded in concentration $(0.012 / 0.006 \mathrm{ppm})$ of $P$. undulate extract, however, other concentration showed moderate activity. However although, it has been reported that $P$. undulate had the greatest activity on $A$. niger. (Muhammad Ajaib et al., 2015). So, it is necessary to do more in vitro experimental in $P$. undulate extract to assess their high effectiveness for genus of fungi.

\section{CONCLUSION}

The results indicated that the extracts of studied plants had a biological activity against $F$. oxysporum f.sp. cicer. So, additional studies on plants under greenhouse and field conditions are still necessary to verify their activity in vivo interaction, also more studies in vitro are needed to determine the active compounds, and to develop new an alternative of synthetic fungicides to be potentially useful for the integrated management of check pea wilt.

\section{ACKNOWLEDGEMENTS}

The authors greatly thank to all Staff of Plant Pathology 
Department (Plant Protection Directorate), Microbiology Department and Photochemistry Department (Medicinal and Aromatic Plants Research Institute)

\section{REFERENCES}

Abd-Ulgadir KS, Suliman SI, Zakria IA, Hassan NA, 2015. Antimicrobial potential of methanolic extracts of Hibiscus sabdariffa and Ricinus communis. Adv Med Plant Res, 3(1): 18-22.

Ajaib M, Aatiqa M, Khalid MK, Shahnaz P, Shazia S, 2015. Pulicaria undulata: A potential phytochemical, antimicrobial and antioxidant source. J Chem Soc Pak, 37(3): 559-566.

Burger Y, Jonas-Levi A, Gurski E, Horev C, Saar U, Cohen R, 2010. Variation in antifungal activity in extracts from Momordica plants. Israel J Plant Sci, 58(1): 1-7.

Chibbar RN, Ambigaipalan P, Hoover R, 2010. Molecular diversity in pulse seed starch and complex carbohydrates and its role in human nutrition and health. Cereal Chem, 87: 342-352.

Dissanayake MLMC, Jayasinghe JAN, 2013. Antifungal activity of selected medicinal plant extracts against plant pathogenic fungi; Rhizoctonia solani, Colletotrichum musea and Fusarium oxysporum. Belihuoya, Sri Lanka. Int J Sci Invent Today, 2(5): 421-431.

Duru ME, Cakir A, Kordali S, Zengin H, Harmandar M, Izumi S, Hirata T, 2003. Chemical composition and Antifungal properties of Essential Oil of three Pistacia species. Fitoterapia, 74: 170-176.

Dwivedi SK, Sangeeta, 2015. Efficacy of some medicinal plant extract against Fusarium oxysporum f. sp. ciceri causing chickpea wilt. Asian J Crop Sci, 7: 138-146.

Jalali BL, Chand H, 1992. Chickpea wilt. Plant Diseases of International Importance. Diseases of Cereals and Pulses. Prentice Hall, Englewood Cliffs, New Jersey. 1: 429-444.

Jibhkate PN, Mondhe MK, Suryapujary SM, 2010. Effect of different soil amendments on wilt complex disease incidence and growth parameters of chickpea (Cicer arietinum L.). Int J Plant Protect, 3(2): 374-378.

Lee SO, Choi GJ, Jang KS, Kim JC, 2007. Antifungal activity of five plant essential oils as fumigant against postharvest and soilborne plant pathogenic fungi. Plant Pathol J, 23(2): 97-102.

Linde GA, Gazim ZC, Cardoso BK, Jorge LF, Tešević V, Glamoćlija J, Soković M, Colauto NB, 2016. Antifungal and antibacterial activities of Petroselinum crispum essential oil. Genet Mol Res, 15(3): gmr.15038538.

Mandhare VK, Suryawanshi AV, 2009. In-vitro evaluation of botanicals against pathogen causing chickpea diseases. J Plant Disease Sci, 4(1): 128-129.

Mukhtar I, 2007. Comparison of phytochemical and chemical control of Fusarium oxysporum f. sp. ciceri. Mycopathology, 5(2): 107-110.

Mukhtar S, Ghori I, 2012. Antibacterial activity of aqueous and ethanolic extracts of garlic, cinnamon and turmeric against Escherichia coli Atcc 25922 and Bacillus subtilis Dsm 3256. Int J Appl Biol Pharm Technol, 3(2): 131-136.

National Committee for Clinical Laboratory Standards (NCCLS, 1999). Performance standards for antimicrobial susceptibility testing, ninth informational supplement. Wayne, Pensilvania document M100-S9. Vol. 19.

Pandey R, Kalra A, Tandon S, Mehrotra N, Singh HN, Kumar S, 2000. Essential oils as potent sources of nematicidal compounds. J Phytopathol, 148: 501-502.

Singh S, Chand H, 2004. Effect of extracts of some medicinal plants on spore germination of (Fusarium oxysporum f. sp. ciceri (Pad) Snyd. \& Hans). Indian J Plant Protect, 32(1): 162-163.
Soliman KM, Badeaa RI, 2002. Effect of oil extracted from some medicinal plants on different mycotoxigenic fungi. Food Chem Toxicol, 40: 1669-1675.

Soumya SL, Bindu RN, 2012. Antifungal efficacy of Capsicum frutescens L. extracts against some prevalent fungal strains associated with groundnut storage. J Agric Technol, 8(2): 739-750.

Srinivasan D, Sangeetha N, Suresh T, Perumalsamy PL, 2001. Antimicrobial activity of certain Indian medicinal plants used in folkloric medicine. J Ethnopharmacol, 74: 217-220.

Sukhdev SH, Suman PSK, Gennaro L, Dev DR, 2008. Extraction technologies for medicinal and aromatic plants. United Nation Industrial Development Organization and the International Center for Science and High Technology. pp 116.
Citation: Teia FKF, Osman A, 2018. Biological activity of selected pla nt ethanolic extracts against phytopathogenic fungi, Fusarium oxysp orum f.sp. cicer. Adv M ed Plant Res, 6(1): 9-12. 